\title{
Improved transformer protection using probabilistic neural network and power differential method
}

\author{
Manoj Tripathy $^{1}{ }^{*}$, R. P. Maheshwari ${ }^{2}$, H. K. Verma $^{3}$ \\ ${ }^{1 *}$ Department of Electrical Engineering, Motilal National Institute of Technology Allahabad, INDIA \\ ${ }^{2,3}$ Department of Electrical Engineering, Indian Institute of Technology Roorkee, INDIA \\ "Corresponding Author: e-mail: manoj_tripathy1@rediffmail.com, Tel +91-9412015058, Fax. +91-532-2445101
}

\begin{abstract}
This article presents a novel technique to distinguish between magnetizing inrush current and internal fault current of power transformer. An algorithm has been developed around the theme of the conventional differential protection method in which parallel combination of Probabilistic Neural Network (PNN) and Power Differential Protection (PDP) methods have been used. Both PNN and PDP method are independent of harmonic contents of differential current. The proposed algorithm is capable of detecting fault and its type in the eventuality of fault in the transformer. Moreover, the combination of PDP method with the PNN makes it capable to detect light internal faults for all ratings of transformers which improve the overall performance of digital differential protection scheme. For evaluation of presented algorithm, relaying signals of various operating conditions of power transformer, including internal faults, external faults, over-excitation and inrush conditions were obtained through modeling of transformer in PSCAD/EMTDC. The performance of proposed amalgamated technique (i.e. combined PNN and PDP method) is compared with the PNN, Feed Forward Back Propagation (FFBP) neural network and the conventional harmonic restraint methods. The results amply demonstrate the capability of the proposed algorithm in terms of accuracy and speed. The algorithm has been implemented in MATLAB.
\end{abstract}

Keywords: Digital differential protection, Protective relaying, Probabilistic neural network, Active power relays, Power differential method.

\section{Introduction}

Protection of large and medium power transformers by means of differential relaying has been a common practice. Differential relaying technique is based on comparison of the transformer's two winding currents. When these currents deviate from a predefined relationship an internal fault is assumed and relay operates. However, during magnetizing inrush condition, very high current of the order of 10-15 times of full load current of transformer may pass through the primary side of power transformer (Sidhu et al, 1992). This high current causes mal-operation of the relay. Therefore, main challenge is to precisely distinguish between magnetizing inrush and fault current to avoid any mal-operation of relay. Literature review suggests that broadly two approaches are applied to discriminate between magnetizing inrush and fault currents; these are Harmonic Restraint (HR) based method and Waveform Identification (WI) based method (Tripathy et al, 2005). The HR method is based on the fact that the second/fifth harmonic component of the magnetizing inrush current is considerably larger than that in a typical fault current. It has been extensively used in comparison of WI method (Tripathy et al, 2005, Wang et al, 2009). However, this method sometimes fail to discriminate between magnetizing inrush and internal fault currents because high second harmonic components are generated during internal faults and low second harmonic component are generated during magnetizing inrush having modern core material of power transformer and due to the presence of shunt capacitance or distributive capacitance in long Extra High-Voltage (EHV) transmission line to which power transformers are connected (Shin et al, 2003). Therefore, the detection of second/fifth harmonic is not a sufficient index to discriminate between the inrush and fault currents of a power transformer.

The second method distinguishes magnetizing inrush current from internal fault current on the basis of WI method. In 1986, Verma and Basha reported microprocessor based waveform differential relaying scheme (Verma et al, 1986). The magnetizing 
inrush current exhibits a characteristic peaked wave, which is caused by asymmetric saturation of the transformer core. In 2006, B. He et al. presented an algorithm to identify inrush current and internal fault current in transformer by using the characteristic of inrush current i.e. peaked wave and dead angle (He et al, 2006). Another group of researchers have investigated the use of wavelet analysis for the classification between fault and healthy state of power transformer. Wavelet transform based methods have better ability of time-frequency location. Their disadvantages are that they need long data window and are also sensitive to noise and unpredicted disturbances, which limit their application in relaying (Arboleya et al, 2006, Tripathy et al, 2009).

It has been demonstrated that the advanced Digital Signal Processing (DSP) techniques and Artificial Intelligence (AI) approaches to power system protection can improve discrimination between normal and fault conditions and facilitate faster, more secure and dependable protection for power transformers. Owing to its superior learning and generalization capabilities Artificial Neural Network (ANN) can considerably enhance the scope of WI method. ANN approach is faster, robust and easier to implement than the conventional waveform approach. The use of neural network can provide an intelligent digital differential protection scheme. Since 1994, many researchers have proposed ANNs based transformer differential protection with various topologies. Most of them used Multilayer Feed Forward Neural Network (MFFNN) with back-propagation learning technique (Bastard et al, 1995, Tan et al, 2004). Another ANN model called Radial Basis Function Neural Network (RBFNN) has also been reported in the literature for power transformer protection (Moravej et al,2003, Borghetti et al, 2008). However, they have so far left some unsolved problems, including those of local minima and slow convergence in training and the need of empirical determination of structure and neural network parameters. In (Tripathy et al,2007), Probabilistic Neural Network (PNN) has been used to discriminate between inrush current and internal fault current of power transformer but it fails to detect turn-turn fault current (i.e. light internal fault current).

This paper presents an algorithm in which PNN is applied in conjunction with Power Differential Protection (PDP) method (Yabe, 1997). The PNN and PDP methods together are used to discriminate between magnetizing inrush current and internal fault current, and also used to determine the type of fault in a power transformer. They are able to detect internal fault current even if the fault current contains a large second harmonic component, as PNN method and combined PNN and PDP method are independent of harmonic components present in operating signal to the relay. PNN method is based on pattern recognization while PDP method is based on the average instantaneous power flowing into the transformer. The proposed amalgamated technique is used to improve the reliability and accuracy as compare to PNN based method and conventional HR method. In this paper, the results of the proposed algorithm are compared with the conventional Discrete Fourier Transform (DFT) based method, Feed Forward Back Propagation (FFBP) based method and optimal PNN based transformer differential protection method.

\section{Probabilistic Neural Network (PNN)}

PNN is a kind of feed forward neural network. The original PNN structure is a direct neural network implementation of Parzen nonparametric Probability Density Function (PDF) estimation and Bayes classification rule (Specht, 1990). The standard training procedure of PNN requires a single pass-over all the patterns of training set (Specht, 1990). This characteristic renders PNN faster to train as compared to FFBP neural network and RBFNN (Specht et al, 1991). The only drawback of PNN is the requirement of larger storage for exemplar patterns. As the computer memory has become very cheap and effective, the cost and size of large storage are no longer of concern these days. PNN is widely used in the area of pattern recognization, nonlinear mapping, fault detection and classification, estimation of probability of class membership and likelihood ratios (Tian et al, 2001).

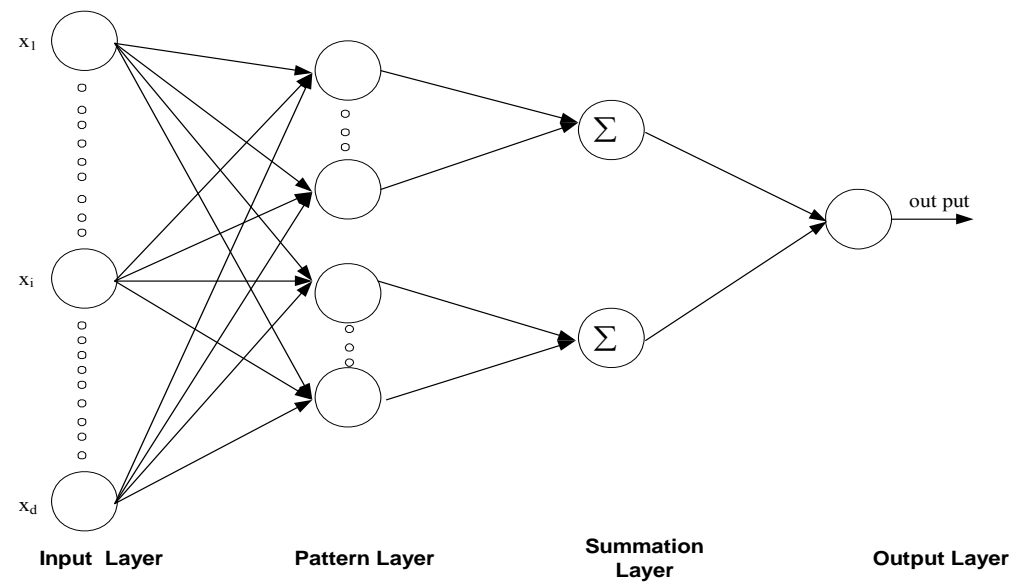

Figure 1. Probabilistic neural network structure

The PNN structure is shown in Figure 1. It is a four layer feed forward neural network that is capable of realizing or approximating the optimal classifier. Generally, Gaussian activation function is used in PNN because if the pattern falls within certain region then the function output is ' 1 ' otherwise function output is ' 0 '. It is not related to any assumption about normal 
distribution. The activation function for PNN is derived from estimates of PDF based on the training patterns as following (Bose et al, 1996):

Let $X \in R^{d}$ be a $d$-dimensional pattern vectors and its associated class be $i \in\left(S_{1}, S_{2}, S_{3}, \ldots, S_{k}\right)$. Where, $k$ is the number of possible class. If a posteriori probability, $P_{r}\left(S_{i} / x\right)$ that is from class $S_{i}$, is by Bayes' rule,

$P_{r}\left(S_{i} / x\right)=\frac{P_{r}\left(x / S_{i}\right) P_{r}\left(S_{i}\right)}{P(x)}$

where,

$P_{r}\left(x / S_{i}\right), \quad i=1,2,3, \ldots, k$ is a priori PDF of the pattern in classes to be separated.

$P_{r}\left(S_{i}\right), i=1,2,3, \ldots, k$ are the priori probabilities of the classes.

$P(x)$ is assumed to be constant.

The decision rule is to select class $S_{i}$ for which $P_{r}\left(S_{i} / x\right)$ is maximum. This will happen if for all $j \neq i$

$P\left(x / S_{i}\right) P_{r}\left(S_{i}\right)>P\left(x / S_{j}\right) P_{r}\left(S_{j}\right)$

It is assumed that a priori probabilities $P_{r}\left(S_{i}\right)$ of the classes are known and the a priori PDF, $P\left(x / S_{i}\right)$ is Gaussian then the estimator for a priori PDF is

$$
\hat{P}\left(x / S_{i}\right)=\frac{1}{(2 \pi)^{d / 2} \sigma_{i}{ }^{d}\left|S_{i}\right|} \sum_{j=1}^{n_{i}} \exp \left[\frac{-\left(x-x_{j}^{i}\right)^{T}\left(x-x_{j}^{i}\right)}{2 \sigma_{i}^{2}}\right]
$$

Where,

$x_{j}^{i}$ is $\mathrm{j}^{\text {th }}$ exemplar pattern from class $S_{i}$

$\left|S_{i}\right|=n_{i}$ the cardinality of the set patterns in class $S_{i}$

$\sigma_{i} \quad=$ Smoothing factor

The input layer has $d$ units, to which the $d$-dimensional input vector $X \in R^{d}$ is applied. The first hidden layer has one pattern unit for each pattern exemplar. Therefore, each such pattern unit may be associated with a generic term depicted in the summation of equation (3) for the $i^{\text {th }}$ class. The second hidden layer contains one summation unit for each class. The output layer is decision layer used for implementing the decision rule by selecting maximum posteriori probability, $p_{r}\left(S_{i} \mid x\right)$ from outputs preceding summation layer for each $i$. The network is constructed by setting weight vector to one of the pattern unit equal to each distinct pattern vector in the training set from a certain class and then connecting the outputs of the pattern units to the appropriate summation units for that class.

For PNN, many algorithms are available in the literature to achieve optimized exemplar pattern set that means removing redundant data or duplicate information. It increases the speed of classification with reduced size of exemplar pattern set while still providing sufficient data to fill the data space (Berthold et al, 1998). The optimal selection of smoothing parameter in PNN classifier is very important factor. The PNN decision boundary varies from a hyper plane to a very nonlinear boundary when the smoothing parameter varies from 0 (Zero) to $\infty$ (infinite). In literature many methodology are reported for the selection of appropriate widths or smoothing factor (Hammond et al, 2004, Musavi et al, 1992). In the present paper a very simple method is used for the calculation of smoothing factor to avoid complex calculation (Bose et al, 1996):

$$
\sigma_{i}=g \mathrm{~d}^{i} \text { javg }
$$

Where,

$\mathrm{d}^{i} \quad=$ Distance between the $\mathrm{j}^{\text {th }}$ exemplar pattern and nearest exemplar pattern in class $i$.

$g=$ Constant that has been by found trial and error.

\section{Power Differential Protection (PDP) Method}

The inflow and outflow of instantaneous power through transformer is according to the magnetic energy stored in transformer winding. Under normal operating condition, about $1 \%$ of the transformer power flows in the magnetizing circuit. In normal operating condition, total power flowing into transformer is about $1 \%$ of the transformer capacity because the copper losses and core losses are of the same order. The PDP method is based on average instantaneous power flow into transformer winding during 
one cycle period T ( $20 \mathrm{~ms}$ for $50 \mathrm{~Hz}$ system). The PDP algorithm calculates the products of instantaneous current and voltage and then calculates the average instantaneous power as given by

$w(t)=\frac{1}{T} \int_{T-t}^{t}\left(u_{1} \dot{i}_{1}+u_{2} i_{2}-r_{1} i_{1}^{2}-r_{2} i_{2}^{2}\right) d t$

To implement the PDP method by digital relay the following mathematical expressions are given as (Yabe, 1997):

$$
\begin{aligned}
& p(t)=u_{1} \mathrm{i}_{1}+u_{2} \mathrm{i}_{2}-r_{1} i_{1}^{2}-r_{2} i_{2}^{2} \\
& w(t)=\frac{1}{\mathrm{~T}} \sum_{n=1}^{N}\left[p\left(t-\frac{n}{N}\right) \mathrm{T}\right] \quad \mathrm{n}=1,2,3, \ldots, N
\end{aligned}
$$

Where,

$u_{1}, u_{2}, i_{1}, i_{2}$ are instantaneous voltage and current at primary and secondary winding terminals respectively.

$r_{1}, r_{2} \quad=$ Primary and secondary winding resistances respectively

$p(t)=$ Instantaneous power

$w(t)=$ Average power of one period time

$N \quad=\quad$ Number of samples per cycle

PDP method is not affected by the harmonic components present in either internal fault current or inrush current because it uses average instantaneous power (Yabe, 1997). In magnetizing inrush condition, average instantaneous power from second period after energization is almost equal to core losses plus stray losses. On the other hand, under an internal fault condition large amount of power is consumed proportional to fault degree (as a portion of winding is short circuited). Therefore, by setting a suitable threshold of average power flowing into the transformer, magnetizing inrush and fault condition can be discriminated.

In the proposed algorithm, the PDP method is utilized to distinguish light internal fault current only as it needs at least one cycle to discriminate different operating condition of power transformer and this is affordable in case of light internal fault only. This technique is capable of detecting fault and its type in the eventuality of fault in transformer. It is operated in conjunction with PNN method. The trip decision of the relay is based on ORing of the two decisions obtained.

\section{Simulation and Training Cases}

During power transformer operation, it encounters any one of the following conditions:

- $\quad$ Normal condition

- Over-excitation condition

- $\quad$ Magnetizing / sympathetic inrush condition

- Internal fault condition

- External fault condition

In normal condition, rated or less current flows through the transformer. In this condition normalized differential current is almost zero (only no load component of current). Whenever, there is large and sudden change in input terminal voltage of transformer, either due to switching-in or due to recovery from external fault, a large current is drawn by transformer from the supply. As a result, the core of transformer gets saturated. This phenomenon is known as magnetizing inrush.

Magnetizing inrush can also occur in an already energized transformer when a nearby transformer is energized. A common situation of sympathetic inrush is encountered when a transformer is energized in parallel with another transformer already in service. The phenomenon which causes inrush current to flow in a previously energized transformer is known as the 'sympathetic inrush'. As the paralleled transformer is being energized by closing the breaker, an inrush current is established in the primary of this transformer and this inrush current has DC component. The DC component of the inrush current can also saturate the already energized transformer, resulting in an apparent inrush current. This transient current, when added to the current of already energized transformer, results in an asymmetrical current that is very low in harmonics. This would be the current flowing in the supply circuit to both transformers. Sympathetic inrush current may not have sufficient amount of the second harmonic in it to prevent the relay from tripping. Sympathetic inrush current depends on same factors on which switching-in and recovery from fault magnetizing inrush current depends. 
PSCAD/EMTDC simulation is used to generate training as well as testing signals under different operating conditions of transformer as mentioned above. The simulation set up is given in Figures 2-4. While simulating magnetizing inrush condition, energization angle, remanent flux in the core and load condition are considered because the magnitude and the wave-shape of magnetizing inrush current depends on these factors.

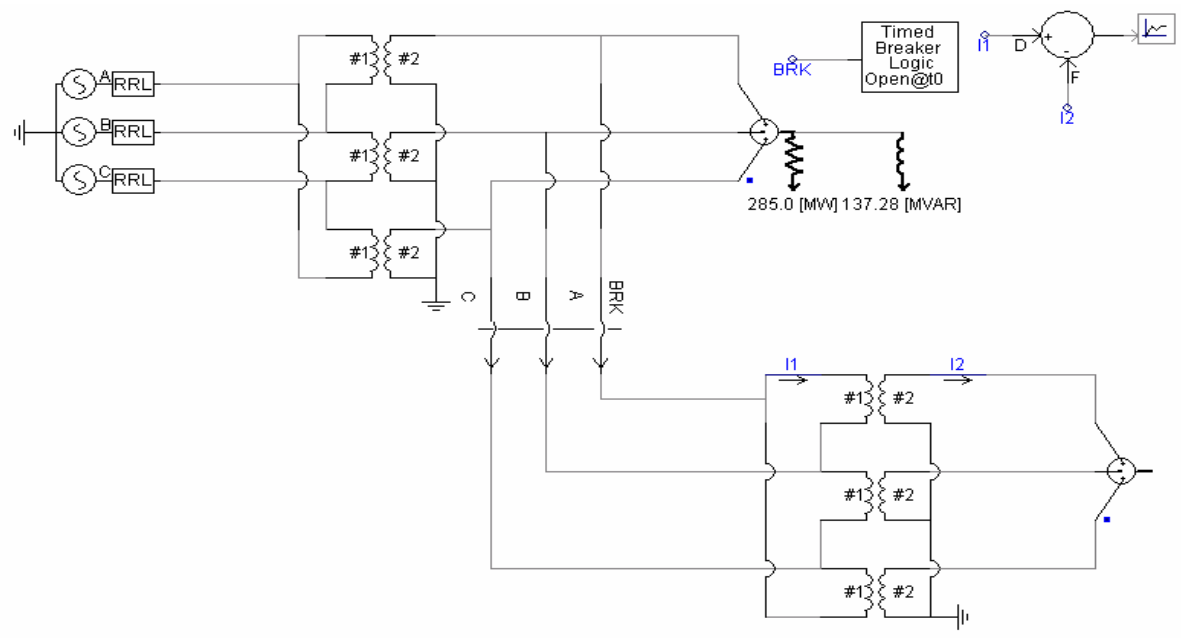

Figure 2. Simulation diagram of magnetizing / sympathetic inrush condition of transformer

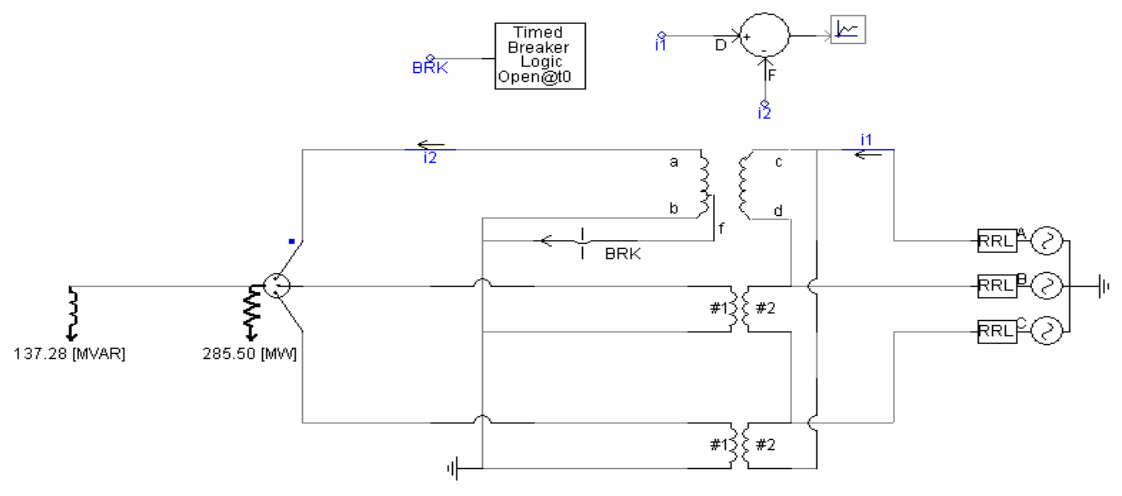

Figure 3. Simulation diagram of phase-to-ground fault under full-load condition of transformer

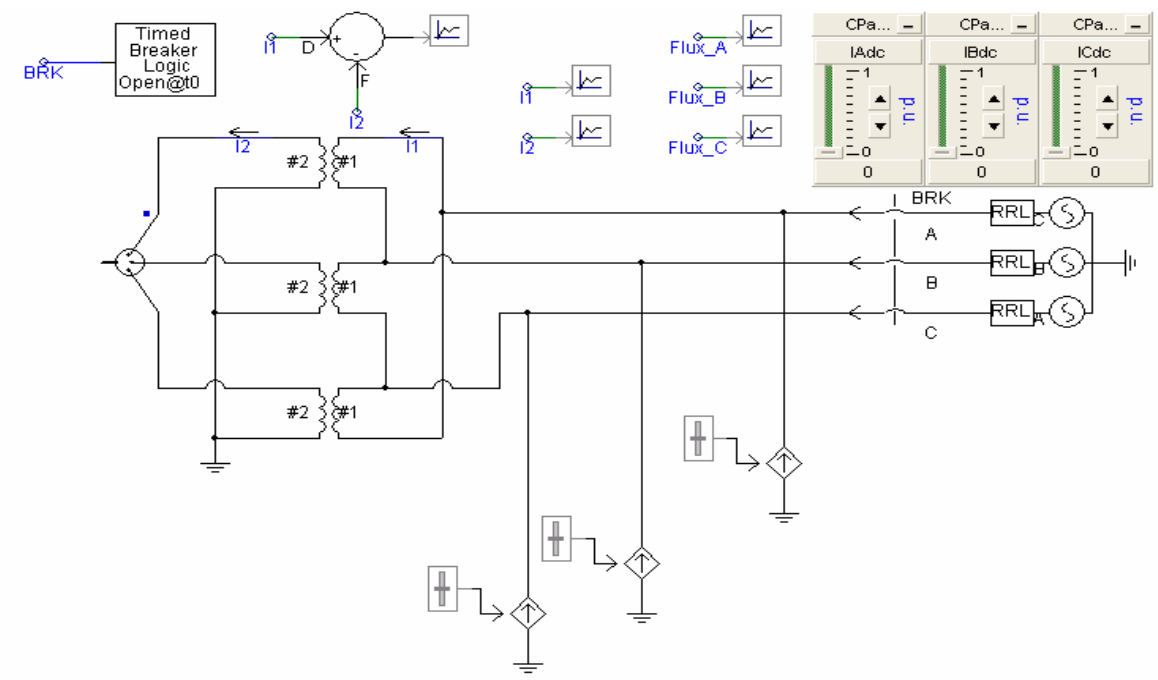

Figure 4. Simulation diagram of magnetizing inrush under no-load considering remanence flux in transformer

Energization angle is varied from 0 to 360 degrees in steps of 30 degrees, and remanent flux is varied from $0 \%$ to $80 \%$ of the peak flux linkages generated at rated voltage with no load and full load conditions to generate training signals, whereas, the testing 
signals are generated by varying energization angle in step of 15 degrees. The desired remanence can be set in un-energized transformer with controlled DC current sources in PSCAD/EMTDC simulation model (Woodford, 2001).

For internal fault, training and testing is formed by simulating fault from $1 \%$ to $99 \%$ of power transformer winding turns. Phaseto-ground fault at different locations as $5 \%, 15 \%, 25 \%, 40 \%$ and $50 \%$ of the winding as well as terminal fault are simulated. The detailed information of power transformer PSCAD/EMTDC simulation model to simulate internal fault (Figure 18) is given in the Appendix-1. Three-phase transformer of 315 MVA at 400/220 kV, 200 MVA at 220/110 kV and 160 MVA at 132/220 kV are modeled using PSCAD/EMTDC. For the simulation of these transformers through PSCAD/EMTDC, the parameters are used that are obtained from M. P. State Electricity Board, Jabalpur India. The test signals so acquired by simulating various operating conditions of a transformer are shown in Figures.5-11. The simulation was done at the rate of 12 samples per cycle of $50 \mathrm{~Hz}$ A.C. supply in view of reported experience on different digital relay designs (Sachdev, 1998). The developed fault detection algorithm was implemented in MATLAB.

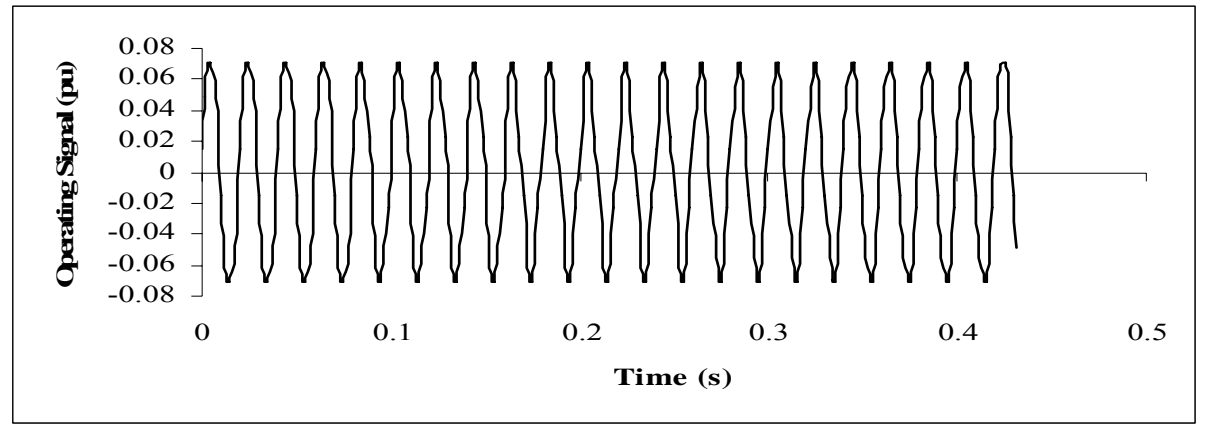

Figure 5. Typical differential current waveform under normal operation

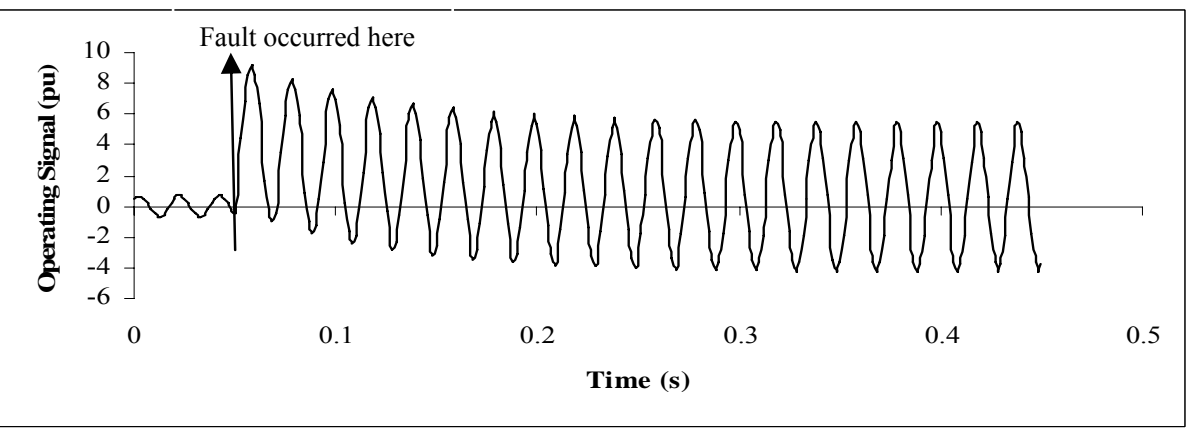

Figure 6. Typical differential current waveform for ground fault

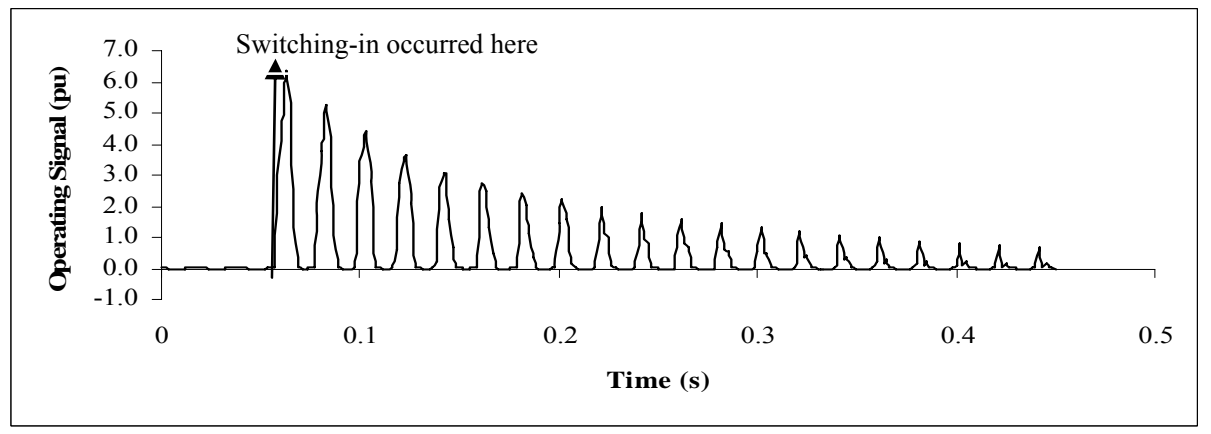

Figure 7. Typical differential current waveform for magnetizing inrush 


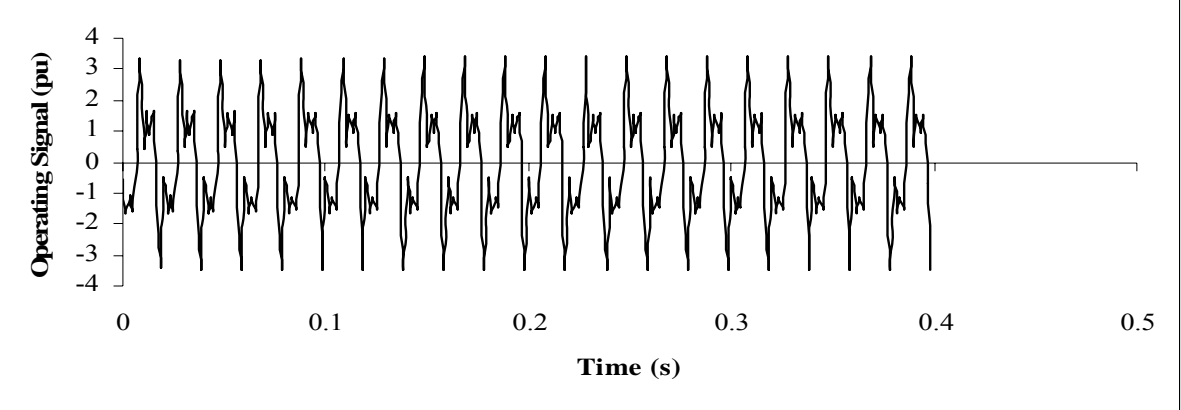

Figure 8. Typical differential current waveform for over-excitation

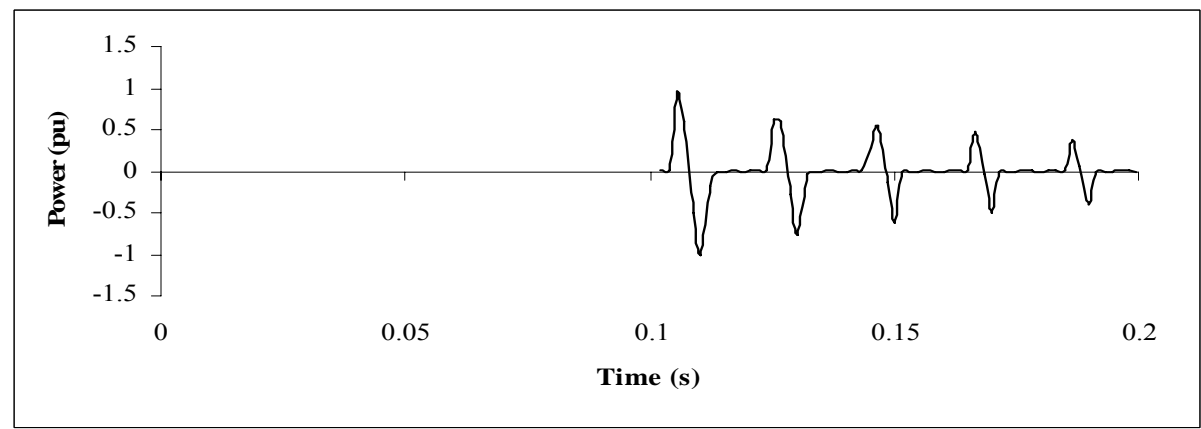

Figure 9. Typical instantaneous power waveform for ground fault

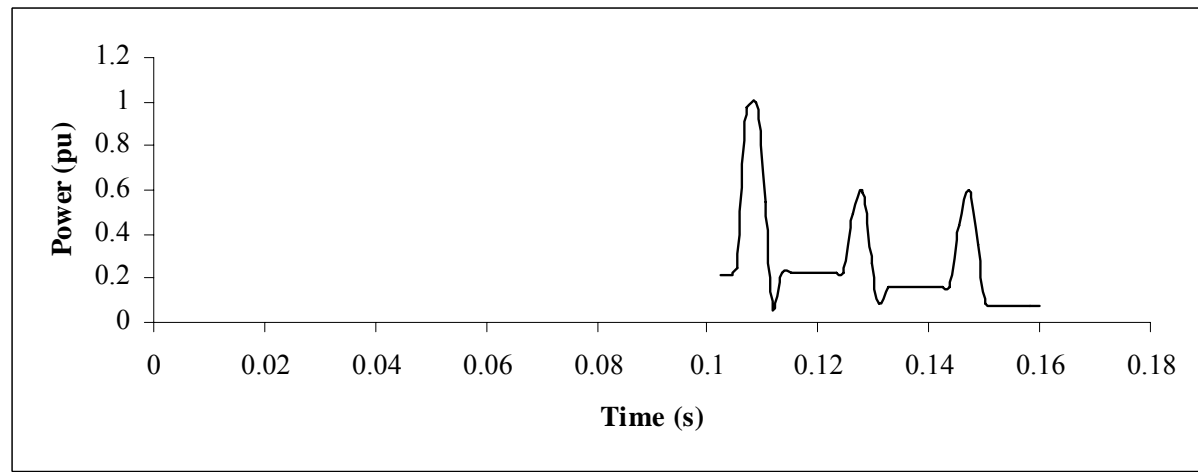

Figure 10. Typical average power waveform for magnetizing inrush

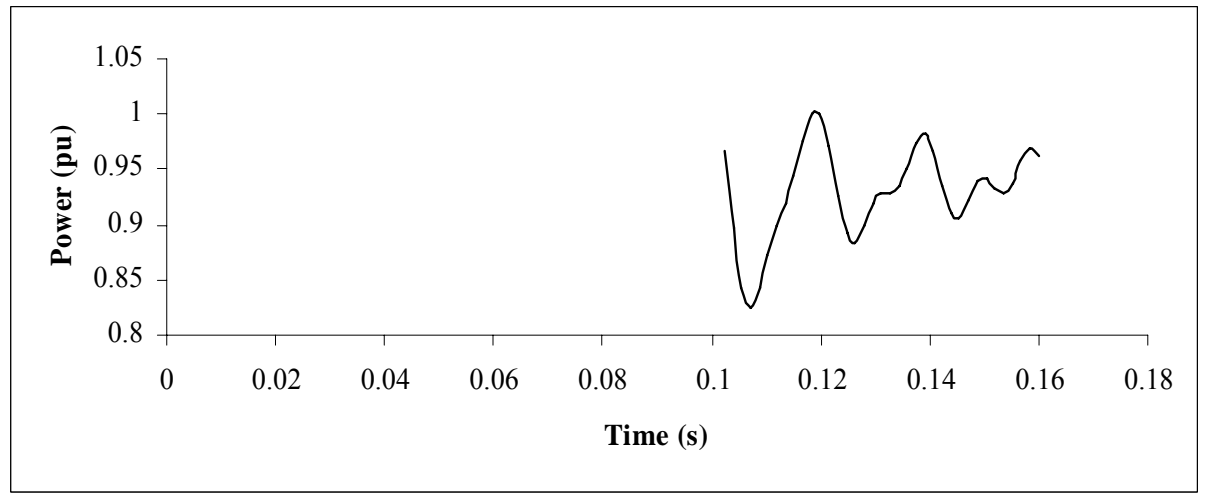

Figure 11. Typical average power waveform for ground fault 


\section{Implementation and Relay Logic}

5.1. Implementation of PNN Based Algorithm and Comparison with FFBP Neural Network

Four layered PNN structure is used as shown in Figure 1. Input layer of PNN model has 12 neurons. The number of neuron of input layer are decided based on the dimension of feature space i.e. 12 samples per cycle. The first hidden layer consists of 777 neurons and it is decided based on total number of exemplar pattern set used to construct the PNN model. In training exemplar pattern set, 444 patterns of magnetizing inrush (including sympathetic inrush patterns), and 333 patterns of faults are used. Second hidden layer has two neurons, as there are only two classes to be classified. In output layer, single neuron is used, as it is the decision layer and it is used for selecting the maximum posteriori probability, from the outputs of the summation layer.

The PNN requires one node or neuron for each exemplar pattern. Various clustering techniques have been used to reduce this requirement to one node per cluster center. Clustered data is required to construct the PNN because the output of first hidden layer is added and this belongs to one specific cluster that is clear from the PNN architecture. To construct an optimized and efficient PNN, the training data are clustered by using K-means clustering (Specht, 1992), and the smoothing factor for each class is calculated by equation (4). The optimal value of multiplication factor $(\mathrm{g})$ is obtained by trial and error method and thus optimal smoothing factor is achieved (see Appendix-2).

Out of 925 sets of data (patterns), 777 patterns sets are used to construct PNN with optimal smoothing factor which is already obtained by the conventional method and remaining 148 sets are used to test the network's generalization ability that are different from those used to train the network. These 148 test exemplar pattern sets contain internal fault and magnetizing inrush condition only as these two conditions are very difficult to discriminate as compared to other operating conditions like external fault condition, over-excitation and normal operation from protection point of view. Out of these 148 cases 74 are that of magnetizing inrush and rest are for internal faults. As other conditions have been taken care before this stage, hence there is no chance of getting exemplar patterns of other operating conditions at this stage.

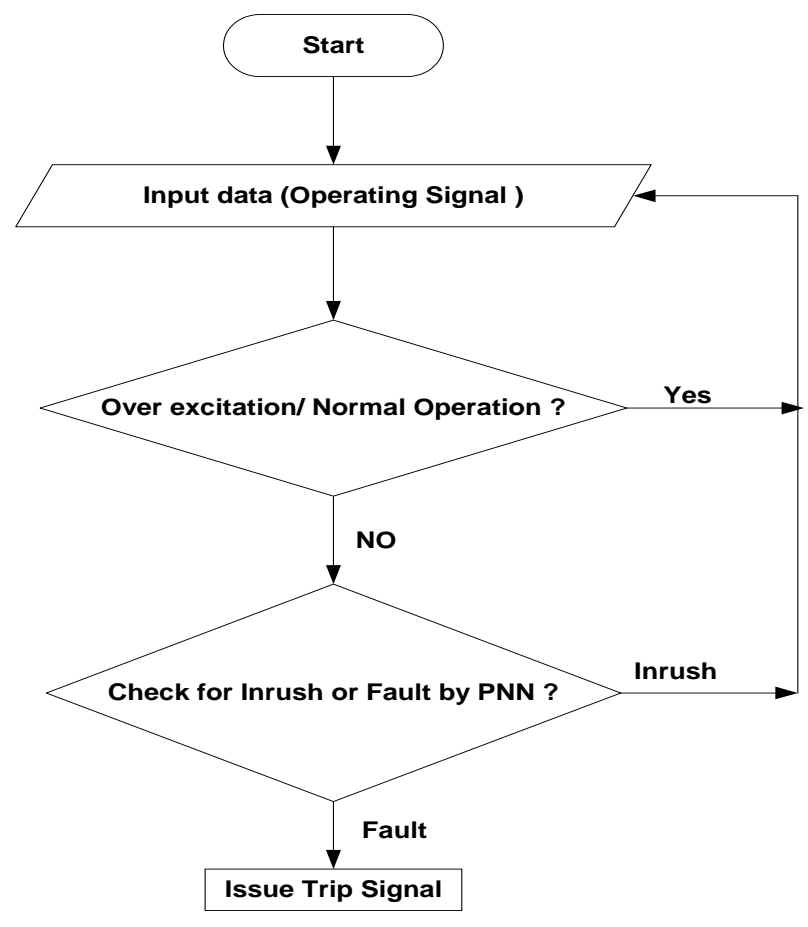

Figure 12. Flow chart of PNN based algorithm

External fault and normal operating condition are ruled-out by comparing two consecutive peaks of operating signal whereas the over-excitation condition is determined by comparing actual value of voltage-to-frequency ratio with its rated value (shown in Figure 12). If these conditions do not exist then the processing is continued to detect the magnetizing inrush and internal fault conditions by PNN. The posteriori probabilities are calculated by the summation layer of PNN and the decision layer selects maximum posteriori probability from the preceding summation layer and on the basis of maximum posteriori probability, the patterns are classified. Accordingly, the PNN gives tripping signal if an internal fault condition is detected. 
Many experiments have been made to evaluate the performance of the PNN model. The fault and magnetizing inrush conditions are tested with all possible patterns. The results are given in Table-1 which presents the natural logarithm of probability of the test pattern to be internal fault or inrush condition. By comparing the magnitude of these probabilities, the test data belongingness is decided. The values given in the Table-1 are the conditional probability estimated by PNN. On the basis of these conditional probability PNN based classifier takes decision i.e. the test data represents either internal fault current or inrush current.

To obtain data for the testing of relaying algorithm fault current magnitude, remanent flux, load condition and switching-in angle are varied to investigate their effects on the performance of the PNN model. Since the profile of magnetizing inrush current wave changes with variation of switching-in instant of transformer hence, it is varied between 0 to 360 degrees. Similarly, due to remanence flux, the magnitude of magnetizing inrush current may be as high as 2 to 6 times to that of the magnetizing inrush without that, although the wave-shape remains same. It is found that the PNN classifier based relay is stable even with such high magnitude of magnetizing inrush current caused by remanence flux whereas the conventional harmonic based relay may maloperate due to such high magnitude of magnetizing inrush current.

Table-1. Conditional probability estimated by PNN

\begin{tabular}{|c|c|c|}
\hline Type of test data & Probability of fault & Probability of inrush \\
\hline Inrush data & 18.901 & 26.004 \\
\hline Fault data & 31.742 & 22.991 \\
\hline
\end{tabular}

The PNN is faster than FFBP neural network. The training required for PNN is very different and much faster than that required for FFBP neural network (Specht et al, 1991). The training process of PNN is one pass without any iteration for the weight adaptation, as against a large number of iteration (epochs) necessary in case of FFBP neural network. As an example, 1000 iterations are required for convergence in case of FFBP neural network implemented by the authors, thereby giving a ratio of about 1000:1 in terms of the training time. Therefore, the PNN is free from the demerits like local minima and slow convergence in training and empirical determination of network structure and parameters. Furthermore, in PNN, single parameter namely smoothing factor is to be tuned whereas in the FFBP neural network at least four parameters like learning rate, momentum coefficient, weights etc. are to be tuned during training of neural network. This makes PNN easy to design and simple in use than the classical ANN.

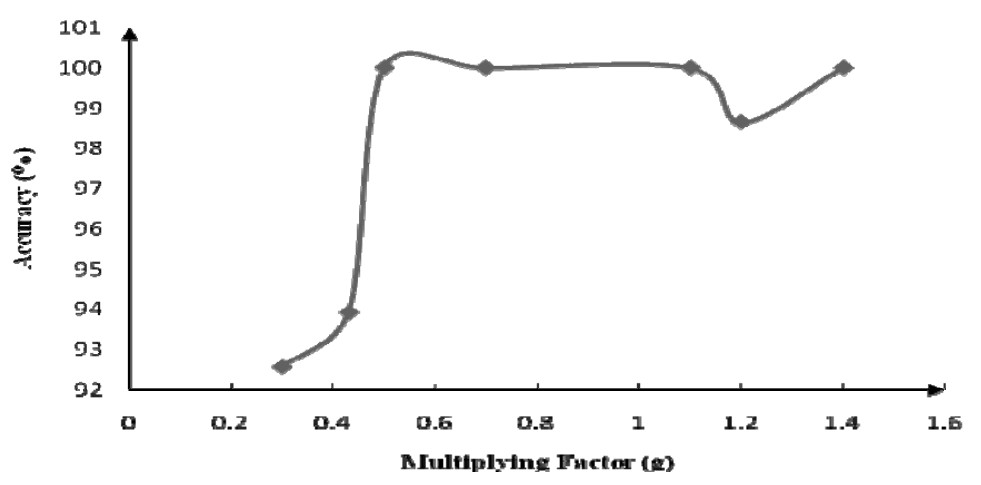

Figure 13. Variation of accuracy versus multiplying factor (g) on 315MVA power transformer using PNN classifier

Table-2 demonstrates that the optimal PNN fails to discriminate some light internal fault i.e. false negative error. This optimal PNN is designed with optimal value of smoothing factor that is obtained by classical method given in Table-3. Figure 13 shows the effect of the multiplying factor on the classification accuracy of a PNN classifier in case of 315MVA power transformer. From the experimental results, it is found that when PNN is trained with one transformer and tested on different rating of transformer, it fails in case of light internal fault condition only. Figure14 illustrates the typical waveform of light internal fault case. The nature of waveform is similar to the typical inrush waveform, and because of similarity in wave-shapes of typical inrush waveform and light internal fault waveform, the boundary of classification becomes narrow and therefore, it is difficult to discriminate the light internal fault cases. Therefore, for such cases PDP technique is applied, which is also independent of harmonic component present in fault current and inrush current. 


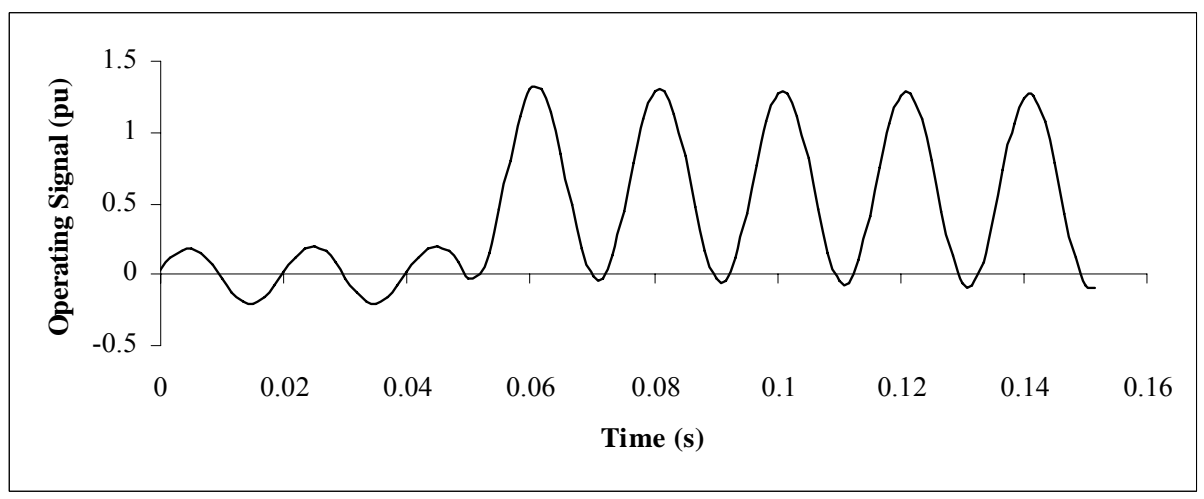

Figure 14. Typical waveform of phase-to-ground fault at $2 \%$ of the winding from the neutral end

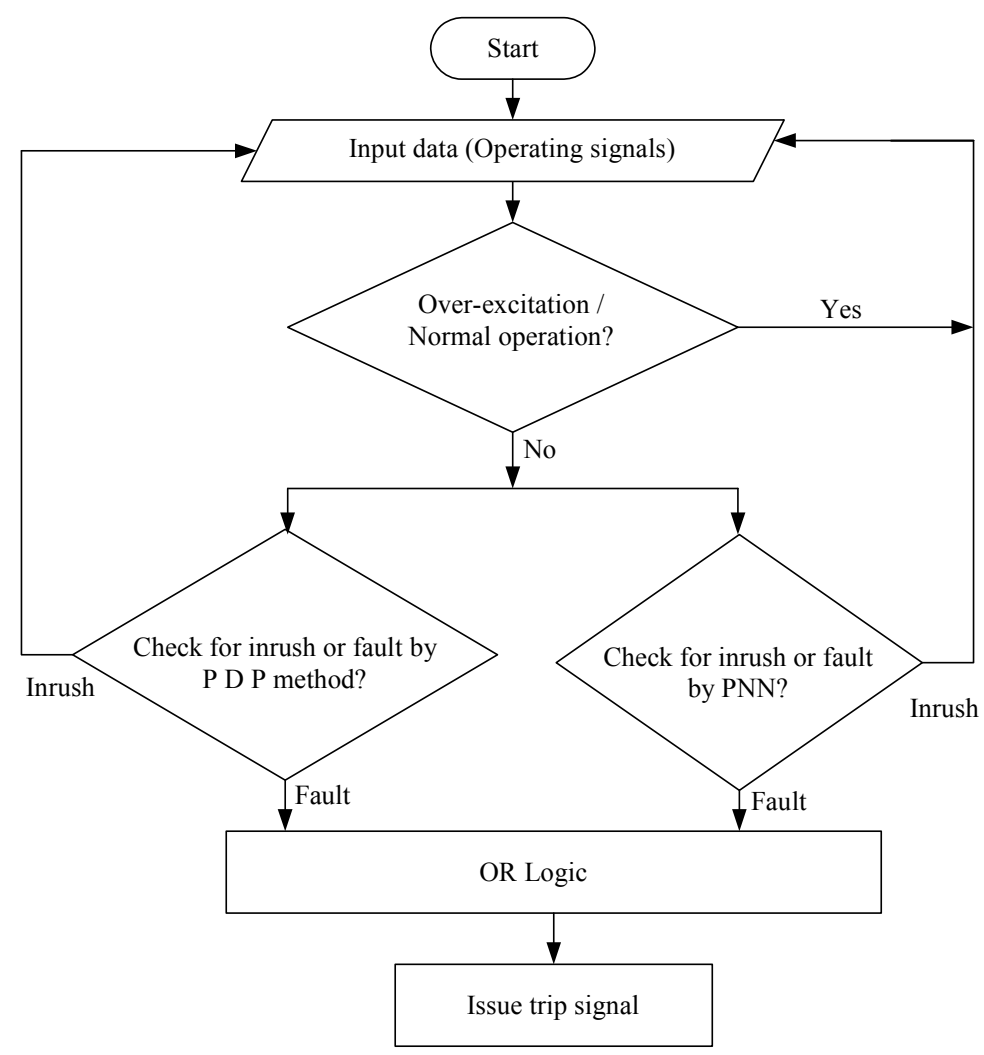

Figure 15. Flow chart of PNN and PDP algorithm

\subsection{Implementation of Hybrid PNN \& PDP method and Result Discussion}

The PNN and PDP methods are parallely operated. The flow chart (Figure 15) illustrates all the steps of the hybrid PNN and PDP method to discriminate between inrush and internal fault conditions. In PDP method instantaneous power (shown in Figure 9) and average power (shown in Figure 11) are calculated by using equation (6) and (7) respectively. From Figure 10 and Figure 11, it is clear that there is large difference in average power after one cycle of time. Therefore, with proper setting of threshold value, operating condition of transformer can be monitored. The threshold value depends on transformer rating and its other parameters. By this method, the type of fault in transformer can also found due to large difference among the threshold values and that for light internal fault, external fault and phase-to-phase fault conditions. This technique is used for the detection of low level internal faults only as there is one cycle delay in decision making which is affordable in this case only, whereas in other cases PNN will 
recognize the different operating conditions of power transformer within half cycle of its occurrence. Therefore, by combining these two methods, fault can be detected with certainty which improve the reliability and stability of differential relaying algorithm. The relay utilize OR logic that means, any input signal either OA or OP is high the relay will issue the trip signal. Where, OA and OP are the output of PNN method and PDP method respectively. O is output of the relay and the high state of output implies the trip signal to be generated.

$$
\text { Classification Error }(\text { in } \%)=\frac{\text { No.of False Positive }+ \text { No.of False Negative }}{\text { Total Number of Test Cases }} \times 100
$$

Classification Accuracy (in \%) $=100-$ Classification Error (in \%)

Table-4 presents the classification in accuracies (in percentage) with FFBP neural network, PNN and combined PNN and PDP method. The classification in accuracy is calculated by using (8). From the results of Table-4, it is clear that the classification ability of PNN is better than the FFBP neural network in this application. However, from Table-4, it is observed that the proposed combined method has ability to discriminate between the light internal fault (turn-to-turn fault) as well as magnetizing inrush condition and classification in accuracy of the combined (PNN and PDP) method has improved as compare to the FFBP neural network and PNN method.

Discrete Fourier Transform (DFT) based harmonic restraint method is implemented, to compare performance of the proposed optimal PNN based algorithm in power transformer differential protection. Figures 16-17 show the ratio of second harmonic to fundamental of the differential current under typical magnetizing inrush and internal fault condition respectively. During one cycle under internal fault condition, the ratio of the second harmonic is quite high and in the same range as in case of magnetizing inrush condition. Therefore, it is difficult to discriminate between internal fault and inrush conditions merely setting a preset threshold. From Figures 16-17, it is also clear that the ratio values are fluctuating, which create problem to decide a preset threshold. Moreover, due to the presence of second harmonic during internal fault condition digital relay will take longer time to make trip decision (one cycle or more than one cycle). In contrast, the optimal PNN based method is able to detect such a fault in 6 ms (half cycle or with in half cycle) except light internal fault (turn-to-turn fault) cases. However, the harmonic restraint method is capable to discriminate between these two conditions but does not seems to be intelligent to take decision in case of fluctuating ratio of second harmonic to fundamental of the differential current due to different loading conditions, severity of internal faults, switching-in angles etc. and hence mal-operation of relay will occur. While the proposed amalgamated technique (i.e. combined PNN and PDP method) is intelligent and more reliable than the conventional harmonic restraint method, FFBP based method and PNN based method.

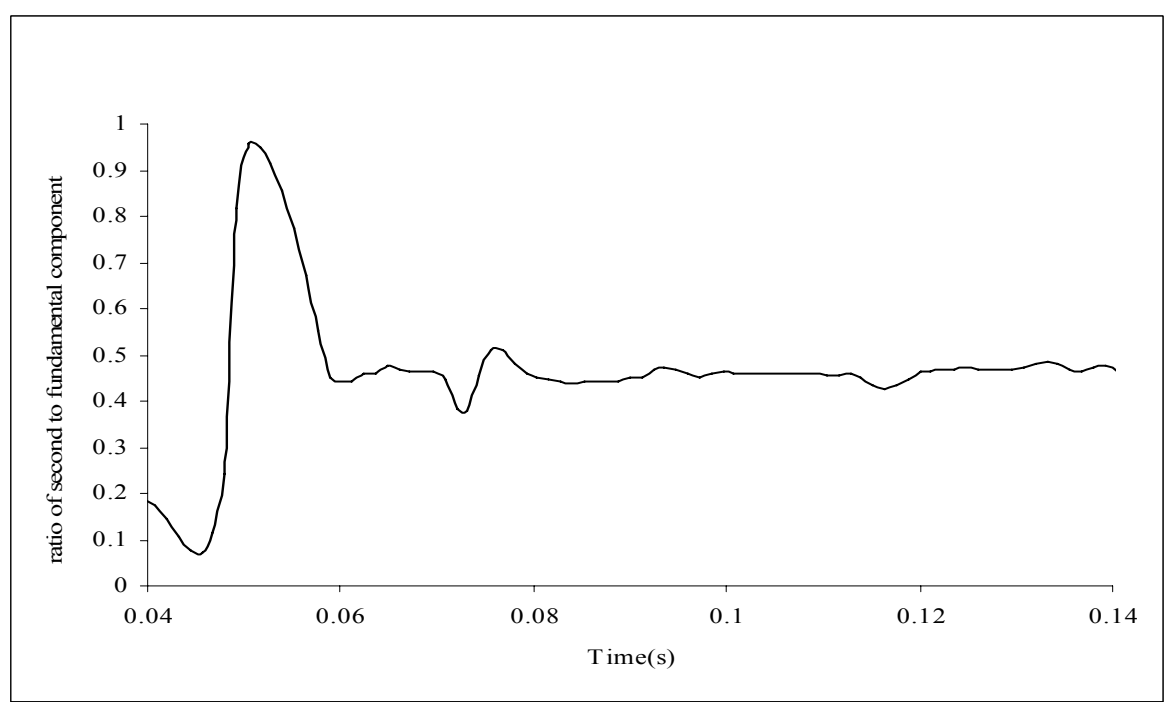

Figure 16. Ratio of second harmonic to fundamental of the differential current under typical inrush condition (inrush occurs at $0.04 \mathrm{sec}$.) 


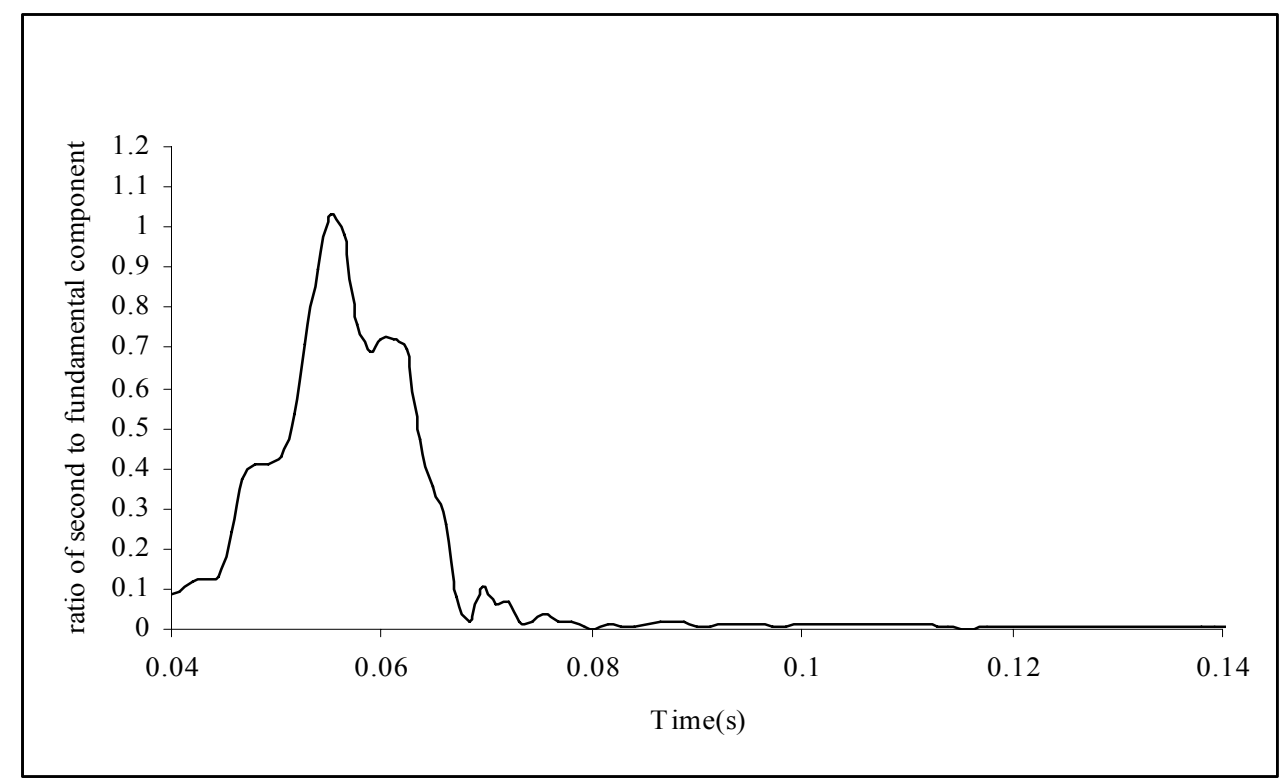

Figure17. Ratio of second harmonic to fundamental of the differential current under typical internal fault condition (internal fault occurs at $0.04 \mathrm{sec}$.)

Table-5 shows the number of post abnormality samples required for decision by FFBP neural network, PNN and PNN conjunction with PDP method based relays. From Table-5, it is clear that the PNN is faster than the FFBP neural network and PNN conjunction with PDP method. However, it fails to recognize some typical light internal fault (turn-to-turn fault) cases whereas the PNN conjunction with PDP method has $100 \%$ classification capability with a reasonable speed as compared among these three methods. In this table actual value indicates the number of post abnormality sample required for detection of a test pattern by concerned algorithm while logical value provides information regarding the of maximum number of post abnormality samples available in a pattern.

Tremendous capability of PNN for classification problems shows suitability for differential transformer protection. It is also immune from the different harmonics contained in operating signals which makes it simpler and robust than the conventional digital filtering algorithms.

Table - 2. Number of false detections in optimal PNN

\begin{tabular}{|c|c|c|c|c|c|c|c|c|c|c|c|c|c|c|c|c|c|c|}
\hline \multirow{6}{*}{$\begin{array}{l}\text { Training } \\
\text { transform } \\
\text { er ratings }\end{array}$} & \multicolumn{18}{|c|}{ Tested transformer ratings } \\
\hline & \multicolumn{6}{|c|}{315 MVA } & \multicolumn{6}{|c|}{200 MVA } & \multicolumn{6}{|c|}{160 MVA } \\
\hline & \multirow{2}{*}{\multicolumn{2}{|c|}{$\begin{array}{c}\text { False positives } \\
\text { Inrush }\end{array}$}} & \multicolumn{4}{|c|}{ False negatives } & \multirow{2}{*}{\multicolumn{2}{|c|}{$\begin{array}{c}\text { False positives } \\
\text { Inrush }\end{array}$}} & \multirow{2}{*}{\multicolumn{4}{|c|}{$\begin{array}{c}\text { False negatives } \\
\text { Faults }\end{array}$}} & \multirow{2}{*}{\multicolumn{2}{|c|}{$\begin{array}{c}\text { False positives } \\
\text { Inrush }\end{array}$}} & \multicolumn{4}{|c|}{ False negatives } \\
\hline & & & \multicolumn{4}{|c|}{ Faults } & & & & & & & & & \multirow{2}{*}{\multicolumn{2}{|c|}{$\begin{array}{l}\text { Phase-to- } \\
\text { ground } \\
\text { fault }\end{array}$}} & \multirow{2}{*}{\multicolumn{2}{|c|}{$\begin{array}{c}\text { Phase-to- } \\
\text { phase } \\
\text { fault }\end{array}$}} \\
\hline & \multicolumn{2}{|c|}{$\begin{array}{l}\text { Switching -in } \\
\text { angles }\end{array}$} & \multicolumn{2}{|c|}{$\begin{array}{l}\text { Phase-to- } \\
\text { ground } \\
\text { fault }\end{array}$} & \multicolumn{2}{|c|}{$\begin{array}{c}\text { Phase-to- } \\
\text { phase } \\
\text { fault }\end{array}$} & \multicolumn{2}{|c|}{$\begin{array}{l}\text { Switching -in } \\
\text { angles }\end{array}$} & \multicolumn{2}{|c|}{$\begin{array}{l}\text { Phase-to- } \\
\text { ground } \\
\text { fault }\end{array}$} & \multicolumn{2}{|c|}{$\begin{array}{c}\text { Phase-to- } \\
\text { phase } \\
\text { fault }\end{array}$} & & $\begin{array}{l}\text { hing -in } \\
\text { agles }\end{array}$ & & & & \\
\hline & $\begin{array}{l}\% \\
* *\end{array}$ & Degrees & $\begin{array}{l}\% \\
* *\end{array}$ & $\begin{array}{c}\% \\
*\end{array}$ & $\begin{array}{l}\% \\
* *\end{array}$ & $\begin{array}{c}\% \\
*\end{array}$ & $\begin{array}{l}\% \\
* *\end{array}$ & Degrees & $\begin{array}{l}\% \\
* *\end{array}$ & $\begin{array}{c}\% \\
*\end{array}$ & $\begin{array}{l}\% \\
* *\end{array}$ & $\begin{array}{c}\% \\
*\end{array}$ & $\begin{array}{l}\% \\
* *\end{array}$ & Degrees & $\begin{array}{l}\% \\
* *\end{array}$ & $\begin{array}{c}\% \\
*\end{array}$ & $\begin{array}{l}\% \\
* *\end{array}$ & $\begin{array}{c}\% \\
*\end{array}$ \\
\hline 315 MVA & 0 & - & 0 & - & 0 & - & 0 & - & 1 & 2 & 0 & - & 0 & - & 0 & - & 0 & - \\
\hline 200 MVA & 0 & - & 0 & - & 0 & - & 0 & - & 0 & - & 0 & - & 0 & - & 2 & 2,5 & 0 & - \\
\hline 160 MVA & 0 & - & 1 & 2 & 0 & - & 0 & - & 2 & 2,5 & 0 & - & 0 & - & 0 & - & 0 & - \\
\hline
\end{tabular}


Table-3. Optimal multiplication factor (g)

\begin{tabular}{|c|c|c|c|}
\hline \multirow{2}{*}{ Trained transformer ratings } & \multicolumn{3}{|c|}{ Tested transformer ratings } \\
\cline { 2 - 4 } & 315 MVA & 200 MVA & 160 MVA \\
\hline 315 MVA & 1.1 & 1.4 & 1.1 \\
\hline 200 MVA & 0.5 & 0.3 & 0.5 \\
\hline 160 MVA & 0.3 & 0.3 & 1.1 \\
\hline
\end{tabular}

Table -4. Classification accuracies (in \%) with FFBP, PNN and combined PNN and PDP method

\begin{tabular}{|c|c|c|c|c|c|c|c|c|c|}
\hline \multirow{3}{*}{$\begin{array}{c}\text { Trained transformer } \\
\text { ratings }\end{array}$} & \multicolumn{9}{|c|}{ Tested transformer ratings } \\
\hline & \multicolumn{3}{|c|}{315 MVA } & \multicolumn{3}{|c|}{200 MVA } & \multicolumn{3}{|c|}{160 MVA } \\
\hline & $\begin{array}{c}\text { FFBP } \\
(\%)\end{array}$ & $\begin{array}{c}\text { PNN } \\
(\%)\end{array}$ & $\begin{array}{c}\text { PNN } \\
\& \\
\text { PDP } \\
(\%)\end{array}$ & $\begin{array}{c}\text { FFBP } \\
(\%)\end{array}$ & $\begin{array}{c}\text { PNN } \\
(\%)\end{array}$ & $\begin{array}{c}\text { PNN } \\
\& \\
\text { PDP } \\
(\%)\end{array}$ & $\begin{array}{c}\text { FFBP } \\
(\%)\end{array}$ & $\begin{array}{c}\text { PNN } \\
(\%)\end{array}$ & $\begin{array}{c}\text { PNN } \\
\& \\
\text { PDP } \\
(\%)\end{array}$ \\
\hline 315 MVA & 99.32 & 100 & 100 & 94.59 & 98.65 & 100 & 98.64 & 100 & 100 \\
\hline 200 MVA & 96.62 & 100 & 100 & 99.32 & 100 & 100 & 98.64 & 96.93 & 100 \\
\hline 160 MVA & 98.64 & 98.65 & 100 & 96.62 & 97.3 & 100 & 100 & 100 & 100 \\
\hline
\end{tabular}

Table - 5. Number of post abnormality samples required for decision by FFBP, PNN and PNN \& PDP method based relays

\begin{tabular}{|c|c|c|c|c|c|c|}
\hline \multirow{2}{*}{ Cases } & \multicolumn{2}{|c|}{$\begin{array}{c}\text { FFBP neural } \\
\text { network }\end{array}$} & \multicolumn{2}{|c|}{ PNN } & \multicolumn{2}{c|}{$\begin{array}{c}\text { PNN and PDP } \\
\text { method }\end{array}$} \\
\cline { 2 - 6 } & $\begin{array}{c}\text { Number of samples } \\
\text { required }\end{array}$ & $\begin{array}{c}\text { Number of samples } \\
\text { required }\end{array}$ & \multicolumn{2}{c|}{$\begin{array}{c}\text { Number of samples } \\
\text { required }\end{array}$} \\
\cline { 2 - 6 } & Actual & Logical & Actual & Logical & Actual & Logical \\
\hline $\begin{array}{c}\text { Magnetizing inrush } \\
\left(\mathbf{0}^{\mathbf{0}}\right)\end{array}$ & 11 & 12 & 05 & 12 & 05 & 12 \\
\hline $\begin{array}{c}\text { Internal fault (Light phase- } \\
\text { to-ground fault at 2\%) }\end{array}$ & 10 & 12 & 06 & 12 & 18 & 24 \\
\hline
\end{tabular}

\section{Conclusions}

This paper presents a novel approach, by amalgamation of PNN and PDP methods, to enhance discrimination between transformer internal fault and magnetizing inrush and to classify the type of fault in power transformer. The PNN is faster than the classical ANNs and easy to design. The reported PNN algorithm is based on wave-shape identification technique which is independent of amount of harmonic contents of operating signal of relay, and suitable for modern power transformers that use high-permeability low coercion core materials. With these core materials high second harmonic components may be generated during internal faults while these components may remain low during magnetizing inrush, and hence the conventional harmonic restraint technique that uses second harmonic component as the indicator of magnetizing inrush may fail. As the PDP method monitors the power flow into transformer irrespective of the harmonic contents of fault currents, and hence is suitable for protection of modern power transformers. In the proposed hybrid method, stability of differential relay is ensured during the magnetizing inrush, sympathetic inrush, over-excitation and external fault conditions. The combination of PDP method with PNN makes it capable to detect light internal faults (turn-to-turn faults) for all ratings of transformers which improve the overall performance of digital differential protection scheme. In addition to that the hybrid method is intelligent, reliable and capable to take decision even in case of fluctuating ratio of second harmonic to fundamental of differential current unlike the conventional harmonic method. Real time implementation of differential relaying using the proposed algorithm applying PNN as the core classifier would essentially require a PNN processor and it is matter of further research. 


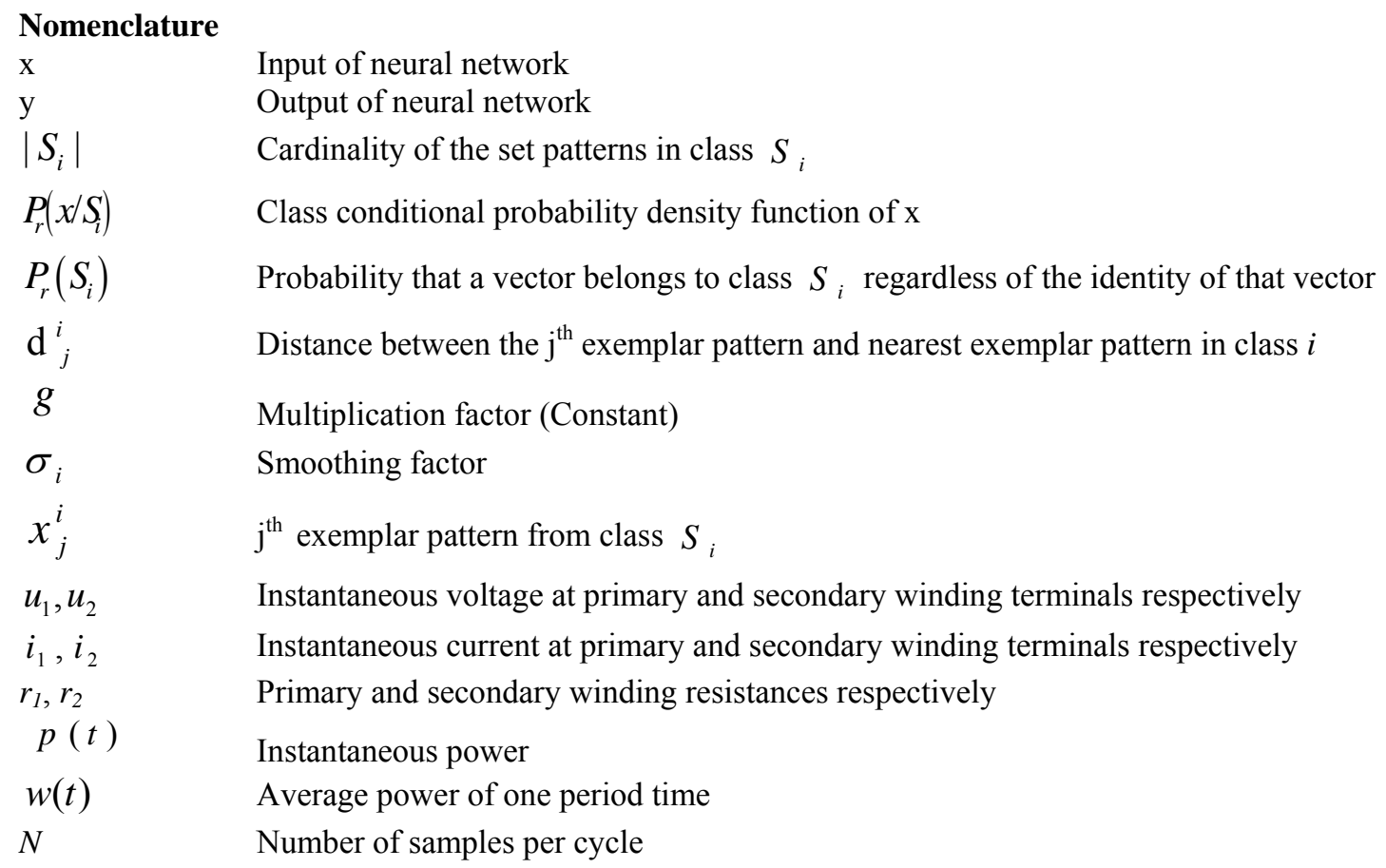

\section{Appendix-1}

Figure 18 shows a typical PSCAD/EMTDC transformer model to simulate internal faults (turn-to-turn, phase-to-ground, and phase-to-phase) at different location of transformer winding from the neutral end of the windings. In this model MVA rating, voltage rating, base frequency, leakage reactance, magnetizing current, and fault location (in \%) etc. can be defined.

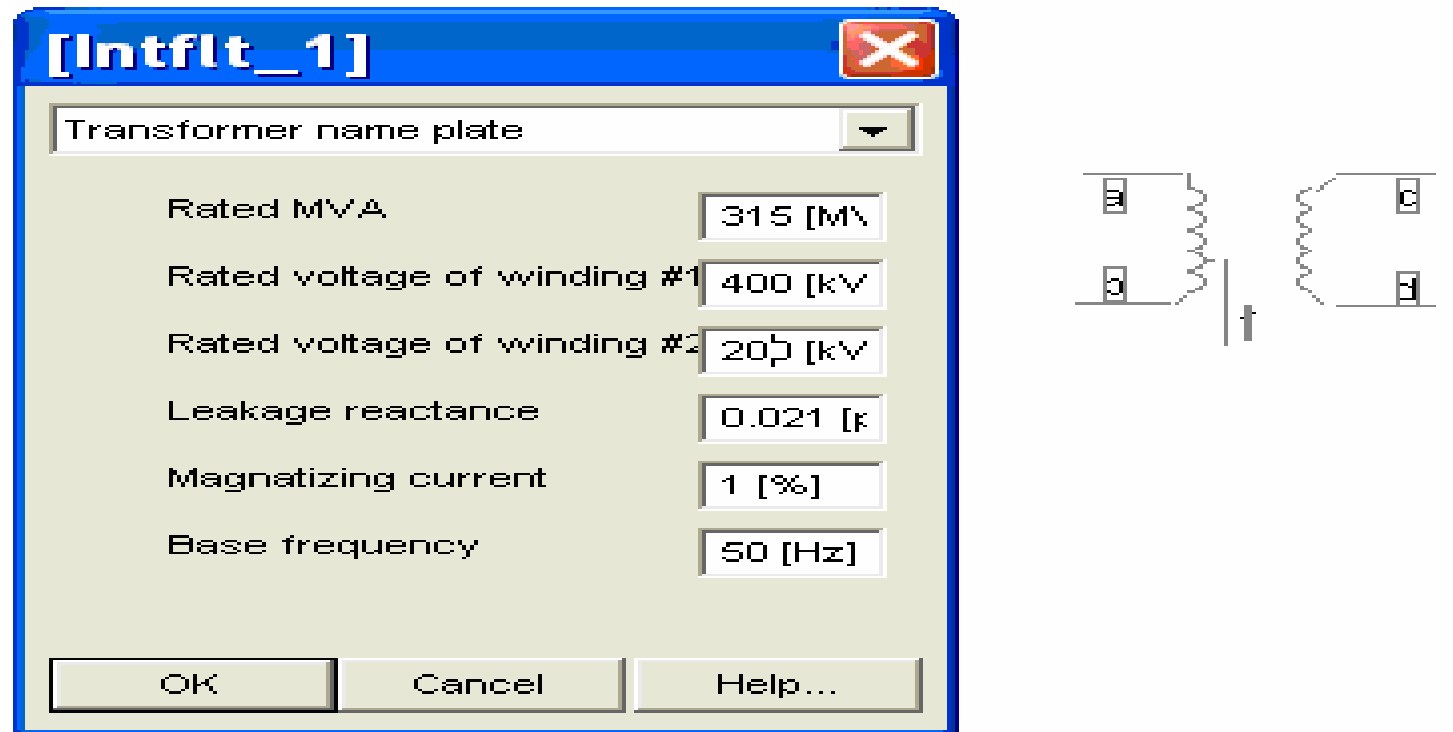

Figure18(a). Typical PSCAD/EMTDC transformer model to simulate internal fault 


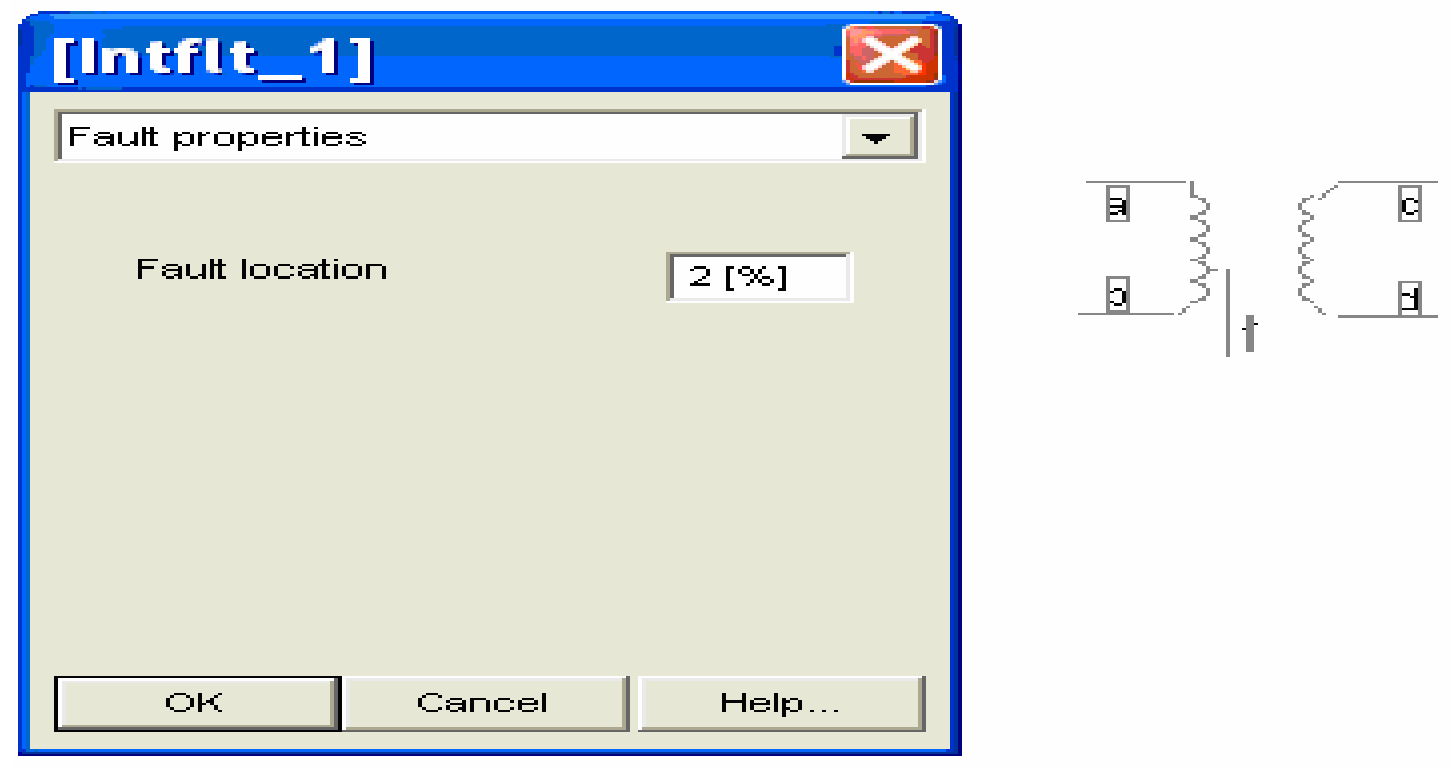

Figure 18(b). Typical PSCAD/EMTDC transformer model to simulate internal faults at different locations

\section{Appendix-2}

i. Calculate smoothing factor $(\sigma)$ by using Euclidean distance between the points representing the training patterns in feature space for each class i.e. $d_{i j}^{k}$ Euclidean distance between $x_{i}^{k}$ and $x_{j}^{k}$ in class $k$.

ii. Take average of Euclidean distances

iii. Select a constant $\mathrm{g}$ by trial and error method

Find optimal value of $g$ based on the application.

\section{References}

Arboleya, P., Diaz, G., Aleixandre, J. G., and Moran, C. G. 2006. A solution to the dilemma inrush/fault in transformer differential relaying using MRA and wavelets. Electric Power Systems and Research, Vol. 34, No. 3, pp. 285- 301.

Bastard, P., Meunier, M., and Regal, H. 1995. Neural network based algorithm for power transformer differential relays. IEE Proc. Generation Transmission \& Distribution, Vol. 142, No. 4, pp.386 -392.

Berthold, M. R., and Diamond, J. 1998. Constructive training of probabilistic neural networks. Elsevier Science, Neurocomputing, Vol. 19, No. 1-3, pp.167-183.

Borghetti, A., Bosetti, M., Silvestro, D. M. and Nucci, A. C. 2008. Continuous-wavelet transform for fault location in distribution power networks: definition of mother wavelets inferred from fault originated transients. IEEE Trans. on Power Delivery, Vol. 2, No. 23, pp.380-388.

Bose, N. K., and Liang, P. 1996. Neural Network Fundamentals with Graphs, Algorithms, and Applications. McGraw-Hill Book Co. International Editions.

Hammond, M. H., Riedel, C. J., Rose-Pehrsson, S. L., and Williams, F. W. 2004. Training set optimization methods for a probabilistic neural network. Elsevier Science, Chemometrics and Intelligent Laboratory System, Vol.71, No.1, pp.73-78.

He, B., Zhang, X., and Bo, Z. Q. 2006. A new method to identify inrush current based on error estimation. IEEE Trans. on Power Delivery, Vol. 21, No. 3, pp.1163-1168.

Moravej, Z., Vishwakarma, D. N. and Singh, S. P.: 2003. Application of radial basis function neural network for differential relaying of a power transformer. Computer and Electrical Engineering, Vol. 29, No. 3, pp.421-434.

Musavi, M. T., Kalantri, K., and Ahmed, W. 1992. Improving the performance of probabilistic neural networks. Proc. IEEE Int. Conf. Neural Networks, Vol. 1, pp.595-600.

Sachdev, M. S. (coordinator). 1988. Microprocessor relays and protection systems. IEEE Tutorial Course Text, (Publi. No.88EH0269-1-PWR).

Shin, M. C., Park, C. W., and Kim, J. H. 2003. Fuzzy logic based relaying for large power transformer protection. IEEE Trans. on Power Delivery, Vol. 18, No. 3, pp.718-724.

Sidhu, T. S., and Sachdev, M. S. 1992. On line identification of magnetizing inrush and internal faults in three phase transformers. IEEE Trans. on Power Delivery, Vol.7, No.4, pp.1885-1891. 
Specht, D. F. 1990. Probabilistic neural network. Neural Networks, Vol. 3, No.1, pp.190-118.

Specht, D. F., and Shapiro, P. D. 1991. 'Generalization accuracy of probabilistic neural networks compared with back-propagation networks. Proc. IEEE Int. Joint Conf. Neural Networks, Seattle, pp. 887-892.

Specht, D. F.1992. Enhancements to probabilistic neural networks. Proc. IEEE Int. Conf. on Neural Networks, Vol. 1, pp.761767.

Tan, K. C., and Tang, H. J. 2004. New dynamical optimal learning for linear multilayer FNN. IEEE Trans. on Neural Networks, Vol. 15, No.6, pp.1562-1568.

Tian, B., Azimi-Sadjadi, M. R. 2001. Comparison of two different PNN training approaches for satellite cloud data classification. IEEE Trans. on Neural Networks, Vol. 12, No. 1, pp.164-168.

Tripathy, M., and Ala, S. 2009. Optimal radial basis function neural network transformer differential protection. Proc. IEEE Int. Conf. on Innovative Ideas towards the Electrical Grids of the Futures, 28 June-2 July 2009, Bucharest, Romania, pp.1-8.

Tripathy, M., Maheshwari, R. P., and Verma, H. K. 2005. Advances in transform protection: a review. Electric Power Components and Systems, Vol. 33, No. 11, pp.1203-1209.

Tripathy, M., Maheshwari, R. P., and Verma, H. K. 2007. Probabilistic neural network based protection of power transformer. IET Electrical Power Application, Vol. 1, No. 5, pp.793-798.

Verma, H. K., and Basha, A. M. 1986. A microprocessor-based inrush restrained differential relay for transformer protection. Journal of Microcomputer Application, Vol. 9, No.4, pp.313 - 318.

Wang, H., and Lin, X. 2009. Studies on the unusual mal-operation of transformer differential protection during the nonlinear load switch-in. IEEE Trans. on Power Delivery, Vol. 4, No. 24, pp.1824-1831.

Woodford, D. 2001. Introduction to PSCAD V3. Manitoba HVDC Research Centre Inc., 400-1619 Pembina Highway, Winnipeg, Manitoba, R3T 3Y6, Canada.

Yabe, K. 1997. Power differential method for discrimination between fault and magnetizing inrush current in transformers. IEEE Trans. on Power Delivery, Vol.12, No.3, pp.1109-1118.

\section{Biographical notes}

Manoj Tripathy was born in Gorakhapur, India, in 1976. He received the B.E. degree in electrical engineering from Nagpur University,Nagpur, India, in 1999, the M. Tech. degree in instrumentation and control from Aligarh Muslim University, Aligarh, India, in 2002, and the Ph.D. degree from the Indian Institute of Technology Roorkee, Roorkee, India, in 2008. He was an Academic Staff Member with Shobhit University, Meerut, India. He is presently Assistant Professor with the Department of Electrical Engineering, Motilal Nehru National Institute of Technology Allahabad, Allahabad, India. His research interests include power system protection, developments in digital protective relay, and power system monitoring. Dr. Tripathy is a Reviewer for various international journals in the area of power systems. He is a member of IE (India), and member of IEEE.

Rudra Prakash Maheshwari was born in Aligarh, India, in 1960. He received the B.E. and M.Sc. (Engg.) degrees in electrical engineering from Aligarh Muslim University (AMU), Aligarh, India, in 1982 and 1985, respectively, and the Ph.D. degree from University of Roorkee, Roorkee, India, in 1996. He was an Academic Staff Member with AMU. He is presently a Professor with the Department of Electrical Engineering, Indian Institute of Technology Roorkee, and a Consultant in the area of small hydro power plants. He has published more than 75 research papers in various international/national journals and conferences. His research interests include power system protection, developments in digital protective relay, and protective relay testing. Dr. Maheshwari is a member of editorial boards and a reviewer for various international journals in the area of power system protection.

H. K. Verma was born in Gojra, India. He received the B.E. degree in electrical engineering from the University of Jodhpur, Jodhpur, India, in 1967, and the M.E. degree in power systems engineering and the Ph.D. degree in electrical engineering from the University of Roorkee, Roorkee, India, in 1969 and 1977, respectively. Currently, he is a Professor and Deputy Director of the Indian Institute of Technology, Roorkee. From 1980 to 1982, he was a Manager (R\&D) of Universal Electrics Ltd., Faridabad (a Birla Group Public Ltd. Co.). His research interests are in the areas of Intelligent instrumentation, digital/ numerical relays, and power system protection, monitoring, and control. He is associated with many Government projects of national importance. He has published a large number of research papers in various international/national journals and conferences.

Received November 2009

Accepted March 2010

Final acceptance in revised form March 2010 